\title{
BIOLOGICAL TRAITS AND SUSCEPTIBILITY OF DELIA ANTIQUA (MEIGEN, 1826) (DIPTERA: ANTHOMYIIDAE) IN ONION
}

\author{
Kamrun Nahar, Shanjida Sultana, Tangin Akter and Shefali Begum* \\ Department of Zoology, University of Dhaka, \\ Dhaka-1000, Bangladesh
}

\begin{abstract}
The pre-oviposition period of mated and unmated female reared on Bangladeshi and Indian onion was $4.5 \pm 0.5,4.37 \pm 0.6$ days and $4.11 \pm 0.09$, $4.45 \pm 0.32$ days, respectively. The oviposition period of mated and unmated female was $5.6 \pm 0.6,6.03 \pm 0.6$ days and $6.48 \pm 0.39,6.5 \pm 0.34$ days reared on Bangladeshi and Indian onion, respectively. The life cycle of Delia antiqua consisted of four definite stages: egg, larva, pupa and adult. The incubation period was $1.38 \pm 0.11$ and $1.25 \pm 0.05$ days; larval period was $5.7 \pm 0.7$ and $5.4 \pm 0.05$ days; pupal period was $6.8 \pm 0.2$ and $6.08 \pm 0.2$ days, respectively. There were three larval instars in $D$. antiqua. To complete the total life cycle it required shorter period in Indian than in Bangladeshi onion. The total life cycle of female was $16.73 \pm 0.89$ and $15.29 \pm 0.45$ days, respectively on Bangladeshi and Indian onion. The difference between the life cycle of female was significant $(p<0.05)$ in Bangladeshi and Indian onion. Fecundity was higher in Indian than in Bangladeshi onion. The fecundity of female D. antiqua reared in Bangladeshi and Indian onion was $75.2 \pm 4.09$ and $89.2 \pm 2.39$, respectively and it was significantly $(\mathrm{p}<0.05)$ varied. Female lived longer than male $D$. antiqua. It was more susceptible in Indian than Bangladeshi onion irrespective of the duration of life cycle and fecundity.
\end{abstract}

Key words: Biological trait, susceptibility, Delia antiqua, onion

\section{INTRODUCTION}

Delia antiqua commonly known as onion fly belonging to the family Anthomyiidae under the order Diptera. Some species of the family are significant agricultural pests, particularly some from the genus Delia, which include the onion fly (Delia antiqua), the wheat bulb fly (D. coarctata), the turnip root fly $(D$. floralis), the bean seed fly (D. platura) and the cabbage root fly (D. radicum). $D$. antiqua is a cosmopolitan pest of crops and the larvae is a major insect pest of onion because onion fly is the optimum pest for the species (Zhang et al. 2014). The family also includes inquilines, commensals and parasitic larvae (Huckett 1971, Suwa and Darvas 1998).

Adult onion fly lays 4 - 8 times more eggs on older plants than younger one (Nault et al. 2011). Host odorants are the main factor for the attraction and stimulation of oviposition in females (Ohta et al. 2014). Oviposition rate of the fly

*Author for correspondence: <shefali@du.ac.bd>.

@2019 Zoological Society of Bangladesh DOI: https://doi.org/10.3329/bjz.v47i2.44343 
increased with the increase in onion stem diameter (Harris et al. 1987). Females can deposit approximately 200 eggs during their lifetime of about 30 days and eggs usually hatch to larva after several days (Ritcey and Chaput 2000).

The 1st instar larva is very harmful because it attacks mainly on new host seedlings and it is a threat to agro ecosystem. Due to the voracious attack of 1 st instar larva, the attacked plant dies before the larvae complete its development stage and then attack the new one (Wilsey et al. 2007). The 2nd and 3rd instar larva do not kill plants but the damaged onion bulbs are not marketable (Brewster 1994). To eat the tissue of the onion plants larva use their hooked mouthparts (Wilsey et al. 2007). The damage by the larvae found high in earliest planting (37\%), lower (21\%) in intermediate plantings but economically unacceptable and lowest (2\%) in late plantings (Werling 2004).

For an effective management of fly pest population, it is necessary to know the biology, breeding behavior and other behavioral aspects of the fly pests and it is anticipated that the outcome of the present study will be of great value in developing suitable and effective control strategies against the experimental fly pest.

\section{MATERIAL AND METHODS}

Different biological traits of Delia antique in Bangladeshi and Indian onion was studied in the laboratory at room temperature $30 \pm 5^{\circ} \mathrm{C}$ and $64-84 \%$ relative humidity and 12L : 12D photoperiod. The life cycle stages and oviposition behavior, fecundity and longevity of $D$. antiqua were studied. In the laboratory rearing of $D$. antique was maintained in rectangular cages $\left(12^{\prime \prime} \times 8^{\prime \prime} \times\right.$ 8) covered with a very thin white transparent cloth and the adult flies were supplied with onion as their food. Adult male and female D. antiqua were collected from a culture maintained in the laboratory. They were allowed to mate 24 hours and they introduced into a rearing cage with the help of an aspirator. Experiments were conducted using the adults emerged from the second generation of the rearing stock.

Egg collection: Eggs were usually laid on the supplied onion. During the oviposition period the female laid eggs in mass or cluster. The egg cluster was collected by keeping them in Petri dish on wet blotting paper or cotton wool.

Larval culture and pupation: A small mass of eggs was gently scraped from the onion and put them in onion remained in the small bowl for larval feeding. The small larval rearing bowl containing mass of eggs on onion subsequently placed in a large plastic bowl with sawdust at base. This bowl was covered by a piece of white cloth to prevent external invasion of same or different fly species. 
They fed up to the 3rd instar and then transferred into the sawdust of large plastic bowl for subsequent pupation.

After completion of pupal development, the pupae were separated from the sawdust by sieving and the pupae kept in petridish and were in turn placed in the adult cage covered with the transparent cloth for emergence of the adult flies. In this way, stock culture was maintained.

\section{Observation of the developmental stages of $D$. antiqua}

Egg: The eggs on the fresh onion were gently scraped from the onion and transferred them to the Petri dish.

The time between egg laying and egg hatching was recorded as incubation period. The maximum and minimum duration of incubation period in hours were recorded. Average value with standard deviation was calculated.

Larva: Just after hatching from the eggs, the larvae (first instar) were transferred to another series of Petri dishes. Five larvae of the D. antique were placed in each Petri dish represented a replicate of five larvae.

Just after hatching, when the larvae ecdysed first, they were termed as the second instar larvae. After the molting of second instar, the third instar larvae appeared which continued up to dropping into the sawdust. The duration of single instar and the total larval period were recorded. During the larval development from first instar to third instar their different morphological structures and change in colour were observed under light microscope.

Pre-pupa: The third instar stopped feeding till pupa formation the stage is termed as pre-pupal stage. The pre-pupal stage continued up to the appearance of pupal stage. The duration of pre-pupal stage was also recorded.

Pupa: The pre-pupal stage subsequently was transformed into the pupal stage. The duration of the pupal stage i.e. time between appearance of pupa till emergence of adult were recorded as pupal period.

Adult longevity: After emergence of adult from pupae, male and female were separated and put them into separate plastic cup. The longevity of male and female was determined by comparing the date of emergence and the date of their death.

This experiment was replicated for five times and carried out through record of the following:

(i) Longevity of mated adult male and female in Bangladeshi and Indian onion.

(ii) Longevity of unmated adult male and female in Bangladeshi and Indian onion. 
Fecundity: Ten pairs (five pairs in Bangladeshi and five pairs in Indian onion) of newly emerged male and female adults were placed in small single pair cages $\left(6^{\prime \prime} \times 6^{\prime \prime} \times 8^{\prime}\right)$ separately and supplied with onion. For fecundity the total number of eggs laid by a female was noted by counting the number of eggs laid during its entire oviposition period.

In order to evaluate the effectiveness of biology of $D$. antique on Bangladeshi and Indian onion, the experimental data were subjected to ANOVA.

\section{RESULTS AND DISCUSSION}

Incubation period: Both the mated and virgin (un-mated) onion fly deposits white elongated eggs. During incubation, the white eggs darkened considerably to a deeper cream before hatching. The incubation period found to vary ranging from 1-2 days. The finding is comparable with Andaloro and Eckenrode (1976), they reported that the eggs hatch into maggots 2 - 3 days after being laid. The mean value of incubation period was recorded as $1.38 \pm 0.11$ days on Bangladeshi and $1.25 \pm 0.05$ days on Indian onion (Table 1). The incubation period of $D$. antique varied significantly $(\mathrm{p}<0.05)$ in Bangladeshi and Indian onion. The first instar larva was seen to emerge through a transverse splitting at the anterior end of the egg shell.

Larval period: The legless maggots were cylindrical, creamy-white in colour. The mean of total duration of larval stages was estimated as $5.7 \pm 0.7$ days in Bangladeshi onion and $5.4 \pm 0.05$ days in Indian onion and it varied significantly $(\mathrm{p}<0.05)$. Each batch of larval instars tends to keep together and collectively create great cavities. The duration of 1st, 2nd and 3rd instar larva were found $1.5 \pm 0.3,2.7 \pm 0.2$ and $1.48 \pm 0.2$ days, respectively in Bangladeshi onion and $2.1 \pm 0.01,2.8 \pm 0.01$ and $1.2 \pm 0.03$ days, respectively in Indian onion (Table 1). The result is quite different from the result of Miles et al. 1958. According to the authors, the successive larval instar required 2, 2 and 5 - 9 days, respectively and the temperature affected the duration of larval stages. This was because in this experiment the size of the Bangladeshi and Indian onion was different.

Pre-pupa and pupal period: At the end of the larval stage, the larvae became sluggish, stopped their movements and feeding. The larva remained in this stage for a few days and prepared themselves for pupation. The colour of the body during this time was lightly reddish. Mean duration of pre-pupal stage was $2.8 \pm$ 0.2 and $2.5 \pm 0.2$ days in Bangladeshi and Indian onion, respectively. The pupa was inactive, motionless and non-feeding stage. The pre-pupa changed soon into the pupa which was dark reddish in colour. In Bangladeshi onion the mean 
duration of pupal stage was $6.8 \pm 0.2$ days and in Indian onion it was $6.08 \pm 0.2$ days (Table 1).

Table.1. Duration of the different stages of the life cycle of mated $D$. antiqua in Bangladeshi and Indian onion

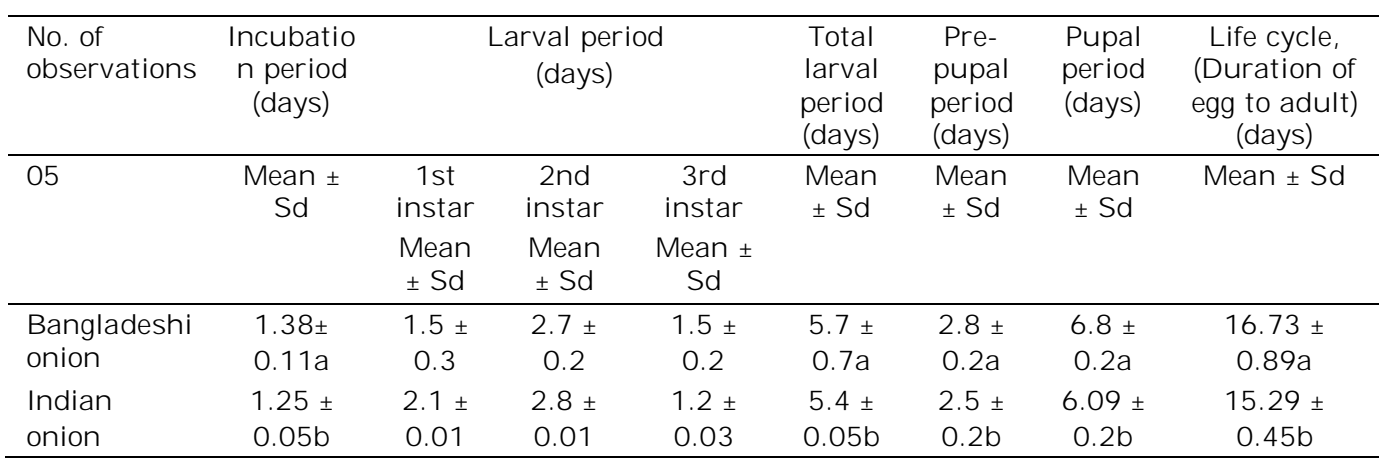

Adult: The puparium was furnished with a cap like lid that popped off by emerging fly. The newly emerged flies were at first pale in colour, soft with unexpanded wings. Later they expanded their wings and turned into ash-grey body. The males usually emerged earlier than the females.

Total life cycle: The total duration of life cycle of $D$. antiqua ranged from 15 17 days in Bangladeshi onion, with a mean of $16.73 \pm 0.89$ days and $14-16$ days in Indian onion, with a mean of $15.29 \pm 0.45$ days (Table 1). The total life cycle varied significantly $(\mathrm{p}<0.05)$ in Bangladeshi and Indian onion.

Pre-oviposition and oviposition period: The pre-oviposition period of mated and virgin fly of $D$. antique started after emergence and finished at the day it started to lay eggs and the mean duration was $4.5 \pm 0.5$ and $4.37 \pm 0.6$ days, respectively in Bangladeshi onion and $4.11 \pm 0.09$ and $4.45 \pm 0.32$ days, respectively in Indian onion. The mean duration of oviposition period of mated and virgin fly of $D$. antique was found $5.6 \pm 0.6$ and $6.03 \pm 0.6$ days, respectively in Bangladeshi onion and $6.48 \pm 0.39$ and $6.5 \pm 0.34$ days, respectively in Indian onion (Table 2). Pre-oviposition and oviposition period for both mated and virgin female were not quite different. According to Spencer and Miller (2002), the distinction between mated and virgin ovipositional patterns may be specifically attributed to difference in: (a) egg maturation, (b) age at ovipositional activation and (c) egg-laying rate.

Percentage of the emergence of larvae, pupae and adult: To observe the hatching percentage of mated female 100 eggs were observed. In Bangladeshi onion, the percentage of hatching from egg to larvae were found $77-90 \%$, from 
larvae to pupae were $70-74 \%$ and from pupae to adult were 60 - $65 \%$ with mean of $81.6 \pm 4.93,71.8 \pm 1.48$ and $61.8 \pm 1.92$, respectively. Similarly, in Indian onion, the percentage of hatching from egg to larvae were found $92-95$, from larvae to pupae were 87 - 90 and from pupae to adult were 81 - $85 \%$ with mean of $93.6 \pm 1.14,89 \pm 1.22$ and $82.6 \pm 1.82$, respectively (Table 3 ).

Table 2. Duration of the pre-oviposition and oviposition period of mated and unmated female of $D$. antiqua, reared in Bangladeshi and in Indian onion

\begin{tabular}{llccc}
\hline Onion & Female & $\begin{array}{c}\text { No. of } \\
\text { observation }\end{array}$ & $\begin{array}{c}\text { Pre-ovipositon } \\
\text { period (days) } \\
\text { Mean } \pm \text { Sd }\end{array}$ & $\begin{array}{c}\text { Ovipositon period } \\
\text { (days) } \\
\text { Mean } \pm \text { Sd }\end{array}$ \\
\hline Bangladeshi & Mated & 10 & $4.5 \pm 0.5 \mathrm{a}$ & $5.6 \pm 0.6 \mathrm{a}$ \\
& Virgin & 10 & $4.37 \pm 0.6 \mathrm{~b}$ & $6.03 \pm 0.6 \mathrm{~b}$ \\
Indian & Mated & 10 & $4.11 \pm 0.09 \mathrm{a}$ & $6.48 \pm 0.39 \mathrm{a}$ \\
& Virgin & 10 & $4.45 \pm 0.32 \mathrm{~b}$ & $6.5 \pm 0.34 \mathrm{~b}$ \\
\hline
\end{tabular}

One hundred eggs of unmated female were also observed to count and compare the hatching percentage with mated female. Result showed that, the percentage of hatching from egg to larvae were found 88 -94, from larvae to pupae were 70 - 79 and from pupae to adult were 60 - 75 with mean of $90.6 \pm$ $2.19,72 \pm 3.94$ and $65.4 \pm 6.77$, respectively, in Bangladeshi onion all the offsprings were male. Similarly, in Indian onion, the percentage of hatching from egg to larvae were found 91 - 95, from larvae to pupae were 81 - 89 and from pupae to adult were $71-80$ with mean of $93.4 \pm 1.67,84.2 \pm 3.35$ and $74.4 \pm$ 3.44,respectively and all the fly were male (Table 3).

Table 3. Percentage of larvae, pupae and adult emerged from mated and unmated female of $D$. antiquain Bangladeshi and in Indian onion

\begin{tabular}{lccccccc}
\hline Reared in & Female & $\begin{array}{c}\text { No. of } \\
\text { observed } \\
\text { eggs }\end{array}$ & $\begin{array}{c}\text { Larva } \\
(\%)\end{array}$ & $\begin{array}{c}\text { Pupae } \\
(\%)\end{array}$ & $\begin{array}{c}\text { Adult } \\
(\%)\end{array}$ & No. of male & $\begin{array}{c}\text { No. of } \\
\text { female }\end{array}$ \\
\hline $\begin{array}{l}\text { Banglade } \\
\text { shi onion }\end{array}$ & Mated & 100 & $81.6 \pm 4.93$ & $71.8 \pm 1.48$ & $61.8 \pm 1.92$ & $31.8 \pm 1.92$ & $30 \pm 1.41$ \\
& Virgin & 100 & $90.6 \pm 2.19$ & $72 \pm 3.94$ & $65.4 \pm 6.77$ & $65.4 \pm 6.77$ & \\
Indian & Mated & 100 & $93.6 \pm 1.14$ & $89 \pm 1.22$ & $82.6 \pm 1.82$ & $40.8 \pm 1.64$ & $39.8 \pm 3.27$ \\
& Virgin & 100 & $93.4 \pm 1.67$ & $84.2 \pm 3.35$ & $74.4 \pm 3.44$ & $74.4 \pm 3.44$ & \\
\hline
\end{tabular}

(larva $\%=\frac{\text { No of hatched larva } \times 100}{\text { Total no.of eggs }} ;$ pupa $\%=\frac{\text { No of pupa emerged } \times 100}{\text { Total no.of larvae }}$; adult $\%=\frac{\text { No of adult emerged } \times 100}{\text { Total no.of pupa }}$ )

Adult longevity and fecundity: The longevity of male was shorter than that of female in both mated and unmated conditions. In case of Bangladeshi the average longevity for mated and unmated male was $11.8 \pm 1.3$ and $12.8 \pm 1.09$ days and for mated and unmated female it was $14.8 \pm 0.84$ and $15.4 \pm 0.89$ 
days, respectively. On the other hand, in Indian onion the average longevity for mated and unmated male was $12.6 \pm 0.55$ and $13.4 \pm 0.89$ days and for mated and unmated female was $14 \pm 1.73$ and $15 \pm 1.22$ days respectively (Table 4). The longevity was found lower in Indian onion than Bangladeshi.

The fecundity of male and female reared in Bangladeshi onion was found $75.2 \pm 4.09$ and in Indian onion was $89.2 \pm 2.39$ (Table 4 ).

Table 4. Fecundity and longevity of onion fly $D$. antiqua in Bangladeshi and Indian onion

\begin{tabular}{|c|c|c|c|c|c|}
\hline \multirow{3}{*}{ Reared in } & \multirow{3}{*}{ Fecundity } & \multicolumn{4}{|c|}{ Longevity (days) } \\
\hline & & \multicolumn{2}{|c|}{ Mated } & \multicolumn{2}{|c|}{ Virgin } \\
\hline & & Male & Female & Male & Female \\
\hline Bangladeshi onion & $75.2 \pm 4.09 \mathrm{a}$ & $11.8 \pm 1.3 \mathrm{a}$ & $14.8 \pm 0.84 a$ & $12.8 \pm 1.09 \mathrm{a}$ & $15.4 \pm 0.89 a$ \\
\hline Indian onion & $89.2 \pm 2.39 b$ & $12.6 \pm 0.55 b$ & $14 \pm 1.73 b$ & $13.4 \pm 0.89 b$ & $15 \pm 1.22 b$ \\
\hline
\end{tabular}

The oviposition period and fecundity were higher in Indian than in Bangladeshi onion, but the total life cycle of $D$. antiqua required less time in Indian than in Bangladeshi onion. From the present study, it may be concluded that the onion fly preferred the Indian than Bangladeshi onion probably due to the juiciness of the Indian than Bangladeshi onion. Only the larva of $D$. antiqua caused damage and because the majority of onion bulbs were stored after harvest, infected onions might have reduced the quality of adjacent onions. It is expected that the study will be very helpful for the development of a suitable control strategy against the onion fly $D$. antiqua.

\section{LITERATURE CITED}

BREWSTER, J.L. 1994. Onions and other vegetable alliums. 1st ed. CAB Intl., Wallingford, UK. pp. 233.

ECKENRODE, C. J. and ANDALORO, J. T. 1976. Insects of onion.Cornell Cooperative Extension factsheet 102GFS750.50.

HARRIS, M. O., MILLER, J R. and PONTI, O.M.B. 1987. Mechanisms of resistance to onion by egglaying. Entomol. Expt. Appl. 43: 279-286.

Huckett, HC. 1971. The Anthomyiidae of California exclusive of the subfamily Scatophaginae (Diptera). Bull. Calif. Insect Survey 12: 1-121.

MILES, M. 1958. Studies of British Anthomyiid flies. IX. Biology of the onion fly, Delia antiqua (Mg.). Bull. Ent. Res. 49: 405-414.

NAUlT, B. A., WERLING, B. P., STRAUB, R. W. and NYROP, J. P. 2011. Delaying onion planting to control onion maggot (Diptera : Anthomyiidae): Efficacy and underlying mechanisms. $J$. Economic. Entomol. 104(5): 1622-1632.

OHTA, S., SETO, Y., TAMURA, K., ISHIKAWA, Y. and MATSUO, T. 2014. Identification of odorantbinding protein genes expressed in the antennae and the legs of the onion fly, Delia antiqua (Diptera : Anthomyiidae). Appl. Entomol. Zool. 49(1): 89-95. 
RITCEY, G. and CHAPUT, J. 2000. Onion maggot control. OMAFRA, 258/605.

SPENCER, J.L. and MILLER J.R. 2002. Lifetime ovipositional patterns of mated and virgin onion flies, Delia antiqua (Diptera: Anthomyiidae). J. Insect. Physiol. 48(2):171-180.

SUWA, M. and DARVAS, B. 1998. In: Contributions to a manual of Palaearctic Diptera. Science Herald, Budapest. 3: 571-616.

WERLING, BP. 2004. Onion maggot Delia antique (Diptera : Anthomyiidae), adult activity and oviposition in New York onion field : Implications for Management. Thesis, Cornell University, New York. pp. 70.

WILSEY, W.T., WEEDEN, CR. and SHELTON, A.M. 2007. Onion maggot life cycle. Cornell University.

ZHANG, Y., HAO, Y., SI, F., REN, S., HU, G., SHEN, L. and CHEN, B. 2014. The de novo Transcriptome and its analysis in the worldwide vegetable pest, Delia antiqua (Diptera : Anthomyiidae).G3 (Bethesda). 4(5): 851-859.

(Manuscript received on 10 August, 2019; revised on 10 November, 2019) 